\title{
COMPARAÇÃO DE MÉTODOS DE ESTIMATIVA DE PROFUNDIDADES DE FONTES MAGNÉTICAS UTILIZANDO DADOS AEROMAGNÉTICOS DA PROVÍNCIA MINERAL DE CARAJÁS, PARÁ
}

\author{
Manuel Gomes Correia ${ }^{1}$, Emilson Pereira Leite ${ }^{2}$ e Carlos Roberto de Souza Filho ${ }^{3}$ \\ Recebido em 19 agosto, 2009 / Aceito em 12 maio, 2010 \\ Received on August 19, 2009 / Accepted on May 12, 2010
}

\begin{abstract}
With the goal of providing an effective analysis for assessment and interpretation of depth to magnetic sources, depth estimates were yielded from high density, aeromagnetic data collected over the Serra Leste region (Carajás Mineral Province, Pará State, Brazil), by three distinct methods: (i) Euler Deconvolution; (ii) Analytic Signal; and (iii) Local Wavenumber. According to the results obtained by these three methods, most of the magnetic sources in the study area are located above $100 \mathrm{~m}$ depth. Statistical analysis showed that the Euler Deconvolution method provides more accurate depth estimates (mean standard error $=6 \%$ ) and that the solutions are better correlated with geological structures and contacts, especially those related to the mineral deposits. For instance, it was verified that the Serra Pelada (Au, Pt, Pd) deposit is located over a NNE-SWW dipping magnetic trend with depths increasing from 25 to $270 \mathrm{~m}$. At this deposit, the estimated depth is about $205 \mathrm{~m}$.
\end{abstract}

Keywords: Carajás Mineral Province, Euler Deconvolution, Analytic Signal, Local Wavenumber.

RESUMO. Com o objetivo de fornecer uma análise eficaz na estimativa e interpretação de profundidades de fontes magnéticas dentro do contexto da geofísica de exploração, foram avaliados três métodos de estimativa de profundidades, aplicando-os a dados aeromagnéticos de alta densidade da região de Serra Leste, inserida na Província Mineral de Carajás, no Estado do Pará. Os métodos compreendidos na avaliação foram os seguintes: (i) Deconvolução de Euler; (ii) Sinal Analítico; e (iii) Número de Onda Local. De acordo com os resultados obtidos por estes três métodos, a maioria das fontes magnéticas na área de estudo situa-se em profundidades menores do que $100 \mathrm{~m}$. A partir de análises estatísticas demonstrou-se que o método da Deconvolução de Euler forneceu os resultados mais precisos na estimativa de profundidades (erro padrão médio $=6 \%$ ) e melhor correlacionados com as estruturas geológicas, especialmente aquelas relacionadas aos depósitos minerais. Por exemplo, foi constatado que o depósito de Serra Pelada (Au, Pt, Pd) está posicionado sobre um lineamento magnético com mergulho de direção NNE-SWW com profundidades que aumentam de cerca de 25 até $270 \mathrm{~m}$. Na posição deste depósito, a profundidade magnética estimada é de cerca de $205 \mathrm{~m}$.

Palavras-chave: Província Mineral de Carajás, Sinal Analítico, Deconvolução de Euler, Número de Onda Local.

Departamento de Geologia e Recursos Naturais, Instituto de Geociências, Universidade Estadual de Campinas, Caixa Postal 6152, 13083-970 Campinas, SP, Brasil. Tel.: (19) 3521-4697; Fax: (19) 3289-1562 - E-mails: ${ }^{1}$ manuel@dep.fem.unicamp.br; ${ }^{2}$ emilson@ige.unicamp.br; ${ }^{3}$ beto@ige.unicamp.br 


\section{INTRODUÇÃo}

A Província Mineral de Carajás (PMC) é considerada uma das principais províncias minerais do planeta e compreende uma das maiores reservas mundiais de minérios de ferro, manganês e ouro, além de conter um grande número de depósitos de cobre, níquel, platina e paládio. Desde a última década, diversos estudos de prospecção (geológicos, geofísicos e de sensoriamento remoto) têm sido implementados na região, como forma de desenvolvimento de pesquisa científica e apoio a empresas de mineração atuantes na área (e.g. Vale).

Uma das maiores aplicações de dados magnéticos tem sido na determinação da profundidade de topo ou centro de fontes magnéticas, sendo útil em diversos campos de aplicação de prospecção geofísica, desde a exploração de hidrocarbonetos, exploração mineral e resolução de problemas ambientais. Devido à sua grande aplicabilidade, tem ocorrido um esforço contínuo visando 0 desenvolvimento de novos métodos de estimativa de profundidades de fontes magnéticas (e.g. Thompson, 1982; Li et al., 2005).

Recentemente, houve ainda um aumento no uso de técnicas de interpretação automática, devido à ampla disponibilidade de computadores de alto desempenho e softwares comerciais (e.g. Reid et al., 1990; Barbosa \& Silva, 2005). Muitas destas técnicas automáticas são capazes de calcular as profundidades magnéticas para uma quantidade substancial de dados interpolados. Neste trabalho, foram aplicados três métodos de estimativa de profundidades magnéticas a dados provenientes de uma região onde a geologia é complexa e as fontes magnéticas são diversas. Os métodos utilizados foram: (i) Deconvolução de Euler; (ii) Sinal Analítico; e (iii) Número de Onda Local. 0 objetivo do trabaIho foi analisar e comparar estatisticamente as soluções e interpretá-las de acordo com o contexto geológico da área de estudo. Desta forma, os resultados deste trabalho podem servir como guia para escolha do método e posterior interpretação em trabaIhos de natureza similar.

0 método da Deconvolução de Euler tem sido o mais utilizado ao longo das últimas duas décadas. Por exemplo, foi aplicado para localizar baterias e tubos de aço soterrados a uma localização e profundidade desconhecida, em Vicksburg, Mississipi, EUA, num estabelecimento do exército dedicado a experimentos hidráulicos (Yaghoobian et al., 1992). Murdie et al. (1999) aplicaram o método de Euler para delinear túneis arqueológicos a profundidades de 5 a 15 metros, em Liverpool, Inglaterra. Diversos exemplos de aplicações em geologia podem ser encontrados na literatura, como por exemplo, nos trabalhos de Reid et al. (1990), Muszala et al. (1999), Barbosa et al. (2000), Hsu (2002) e Oliveira et al. (2005).
0 método do Sinal Analítico foi aplicado para estudar limites geológicos numa região a leste do Canadá, sobre Cape Breton, Newfoundland e mapear a profundidade da bacia de Sydney, localizada na Austrália (Roest et al., 1992). Aboud et al. (2003) estimaram as profundidades das estruturas geológicas do arcabouço da bacia de Gebel El-Zeit, no Egito, utilizando os métodos de Sinal Analítico e da Deconvolução de Euler em conjunto. Smith \& Salem (2005) aplicaram o método a dados magnéticos coletados para exploração mineral de ouro na área de Timmins, Ontário, Canadá, a partir do qual foi possível a delimitação da profundidade e susceptibilidade magnética dos depósitos.

0 método do Número de Onda Local foi aplicado por Thurston \& Smith (1997) para mapear 0 embasamento pré-cambriano situado abaixo de uma camada sedimentar à noroeste de Alberta e nordeste de British Columbia, no Canadá. Li et al. (2005) aplicaram o Número de Onda Local, conjuntamente com outros métodos, em estudo geológico e geofísico integrado na Bacia de Williston, utilizando informações de geologia de superfície, furos de sondagem, mapa gravimétrico e linhas sísmicas 0s resultados obtidos com o método e a posterior integração com outros dados geológicos e geofísicos permitiram interpretar algumas estruturas e falhas geológicas de maneira bastante precisa.

\section{CONTEXTO GEOLÓGICO}

A Província Mineral de Carajás (PMC; Fig. 1) está localizada no sudeste do Cráton Amazônico e faz parte da Província Amazônia Central. Foi formada e estabilizada tectonicamente no Arqueano e pode ser dividida em duas unidades geotectônicas: a norte, localiza-se o Cinturão de Cisalhamento Itacaiúnas (Araújo et al., 1988); e ao sul, o terreno granito-greenstone Rio Maria (Huhn et al., 1988).

Dentro da porção norte da PMC, 0 embasamento Arqueano compreende granulitos do Complexo Pium ( 3,0 Ga; Rodrigues et al., 1992) e migmatitos e gnaisses tonalíticos e trondjemíticos do Complexo Xingu ( 2,8 Ga; Machado et al., 1991). As rochas do embasamento são sobrepostas pelas unidades metavulcanosedimentares do Grupo Rio Novo e do Supergrupo Itacaiúnas (2,76 Ga; grupos Igarapé Salobo, Igarapé Pojuca, Grão Pará e Igarapé Bahia; Wirth et al., 1986; Docegeo, 1988; Machado et al., 1991). Estas sequências metavulcano-sedimentares compreendem formações ferríferas, rochas sedimentares clásticas, rochas piroclásticas e vulcânicas básicas e félsicas metamorfisadas (Hirata et al., 1982; Wirth et al., 1986; Docegeo, 1988; Machado et al., 1991).

0 Grupo Rio Novo e o Supergrupo Itacaiúnas encontramse sobrepostos por uma extensa sucessão de rochas metassedimentares (2,681 $\pm 5 \mathrm{Ma}$; Trendall et al., 1998), incluindo meta- 


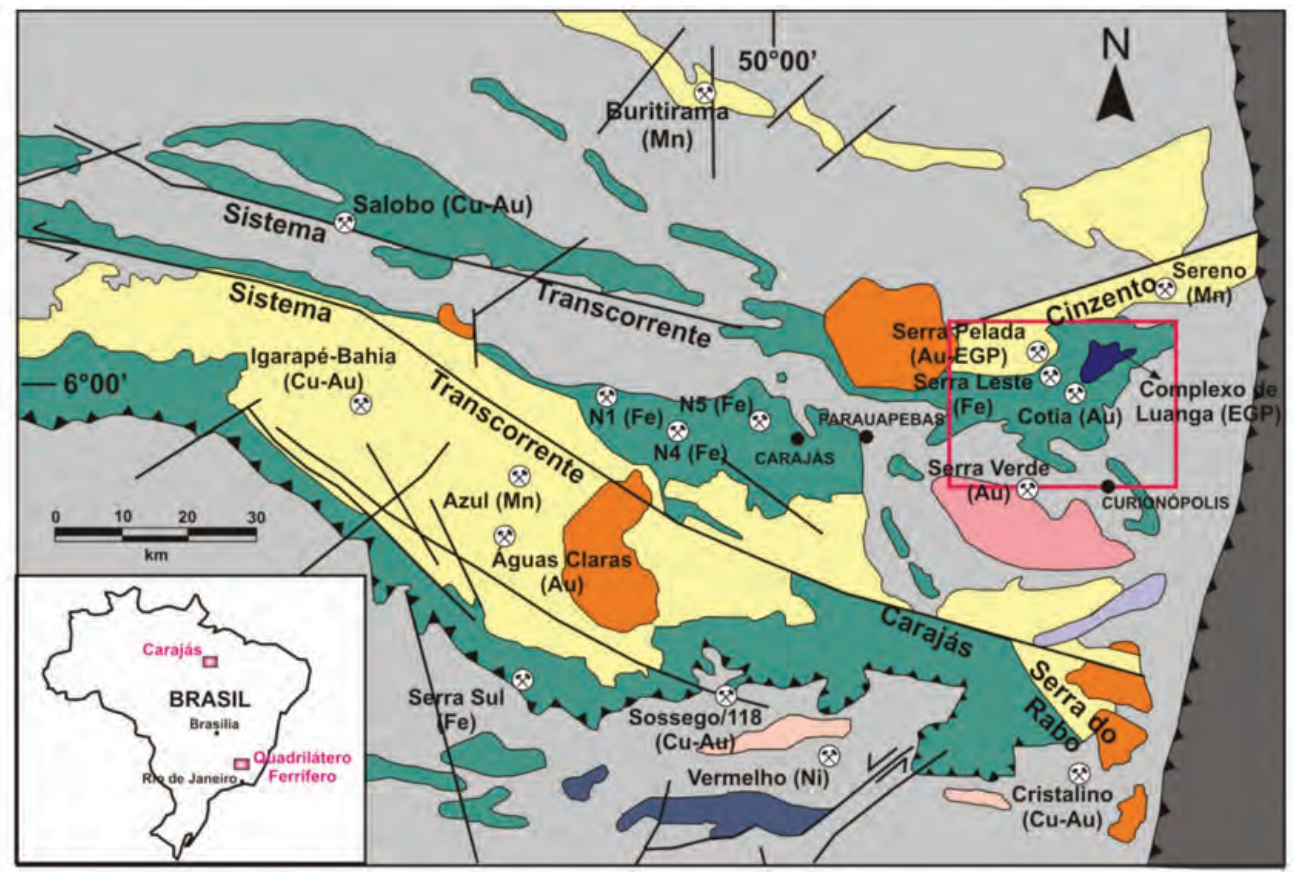

\section{NEOPROTEROZÓICO}

\section{Cinturão Araguaia ARQUEANO}

\section{Granitos Eoarqueanos}

Seqüências metassedimentares (Grupo Rio Fresco/ Formaçẫo Águas Claras)

Seqüências metavulcano-sedimentares Supergrupo Itacaiúnas

Gnaisses e migmatitos (Complexo Xingu)

Granulitos (Complexo Pium)

- Cidades

\section{PALEOPROTEROZÓICO}

Granitos anorogênicos

Rochas máficas (Gabro Santa Inês) e máficas-ultramáficas (tipo Vermelho)

Complexo máfico-ultramáfico (Luanga)

Rochas dioriticas e graníticas (Suíte Plaquê)

\section{Contatos geológicos}

\section{Falhas}

* Ocorrências minerais e minas

Figura 1 - Mapa geológico simplificado da região da Serra dos Carajás (adaptado de Monteiro et al., 2007) e principais depósitos minerais da Província Mineral de Carajás. A região de Serra Leste está destacada dentro do retângulo magenta.

conglomerados, meta-arenitos, mármores dolomíticos e metasiltitos, originalmente depositados em ambiente marinho-raso à fluvial, conhecida como Grupo Rio Fresco (Docegeo, 1988) ou Formação Águas Claras (Araújo et al., 1988).

A complexa evolução estrutural da PMC e o metamorfismo das unidades Arqueanas são atribuídos ao desenvolvimento de zonas de falhas de alto mergulho, constituindo um trend regional E-W, que evidenciam episódios de movimentação crustal (Holdsworth \& Pinheiro, 2000). A Zona de Cisalhamento Itacaiúnas, de natureza dúctil, foi desenvolvida há cerca de 2,8 Ga, na fase de movimentação transpressiva sinistral. A fase de trans- tensão destral originou os sistemas de falhas strike-slip de Carajás e Cinzento entre 2,7-2,6 Ga. 0 regime transpressional sinistral ocorrido há cerca de 2,6 Ga resultou em deformação moderada à alta das rochas imediatamente adjacentes aos sistemas de faIhas de Carajás e Cinzento. Há 1,9 Ga, eventos de transtensão ou extensão foram acompanhados pela colocação de granitos anorogênicos e enxames de diques (Holdsworth \& Pinheiro, 2000).

Os granitos alcalinos sin-tectônicos (2,76-2,74 Ga; Complexo Granito Estrela, Suíte Plaquê, Planalto e Serra do Rabo; Dall'Agnol et al., 1997; Barros et al., 2001) intrudem as sequências metavulcano-sedimentares Itacaiúnas e Rio Novo. Outras 
intrusões Arqueanas incluem Vermelho, Onça, Jacaré-Jacarezinho e o Complexo máfico-ultramáfico Luanga (2763 $\pm 6 \mathrm{Ma}$, Machado et al., 1991), bem como diques e soleiras de gabros com idades de 2,76-2,65 Ga (Galarza et al., 2003; Pimentel et al., 2003). Magmatismo paleoproterozóico ocorre em várias partes da PMC e é representado por granitos intraplaca, alcalinos a sub-alcalinos, do tipo A ( 1,88 Ga; granitos Serra dos Carajás, Cigano, Cigano, Pojuca, Salobo, Musa, Jamon, Seringa, Velho Guilherme e Breves; Dall'Agnol et al., 1994; Tallarico et al., 2004).

\section{GEOLOGIA LOCAL DA ÁREA DE SERRA LESTE}

Em Serra Leste (Fig. 2), podem ser reconhecidos anfibolitos, xistos, metagrauvacas, rochas metavulcânicas toleiíticas e gabros do Grupo Rio Novo (Hirata et al., 1982), além de xistos máficos e formações ferríferas do Grupo Grão Pará (Supergrupo Itacaiúnas). Esta área tem $716 \mathrm{~km}^{2}$ e é definida por um polígono limitado pelos paralelos $634.000 \mathrm{E}$ e $666.000 \mathrm{E}$ e pelos meridianos $9.325,000 \mathrm{~N}$ e 9.347,400 N, na zona $22 \mathrm{~S}$ do sistema UTM.

0 Grupo Rio Novo foi intrudido pelos complexos máficoultramáficos Luanga, Luanga Sul, Luanga Norte, Orion, Afrodite, Formiga, Pegasus e Centauro. 0 Complexo Luanga é o principal deles, contendo mineralizações de cromo e de Elementos do Grupo da Platina (EGP) (2763 \pm 6 Ma, Machado et al., 1991). Recentemente, foram aplicados métodos de mapeamento do potencial mineral (Leite \& Souza Filho, 2009a) e análise espacial de dados aerogeofísicos e geológicos (Souza Filho et al., 2007), visando principalmente 0 estudo das mineralizações de EGP nesta área.

Um cinturão alongando na direção NE pertencente ao Grupo Rio Fresco/Formação Águas Claras (2681 $\pm 5 \mathrm{Ma}$; Trendall et al., 1998) repousa sobre 0 Grupo Rio Novo, formando uma inconformidade (Docegeo, 1988). Esta unidade compreende quartiztos ricos em sericita, meta-arenitos ricos localmente em manganês, meta-siltitos carbonáticos, mármores dolomíticos com lentes de rochas ricas em clorita-talco, e metaconglomerados com formações ferríferas, quartzito e clastos de siltitos dentro de uma matriz de sericita-quartzo foliada (Tallarico et al., 2000). Os grupos Rio Fresco e Rio Novo, bem como o Complexo Luanga, sofreram dobramento e metamorfismo de baixo grau devido à reativação do sistema de falhas strike-slip do Cinzento (Suita \& Nilson, 1988). A terminação leste deste sistema define o Splay Divergente de Serra Pelada (SDSP) (Pinheiro \& Holdsworth, 1997).

Três episódios de magmatismo de granitóides são reconhecidos na área de Serra Leste. 0 mais velho é representado pela colocação do complexo alcalino sin-tectônico Granito Estrela
(2763 \pm 7 Ma; Barros et al., 2001). 0 Granito Estrela aflora como um corpo elíptico alongado na direção EW concordante com as estruturas regionais. Uma auréola tectono-termal foi produzida no envelope da sequência metavulcano-sedimentar (Barros \& Barbey, 2000). Outras intrusões são representadas pelo granito anorogênico Cigano (1883 \pm 2 Ma; Machado et al., 1991), exposto cerca de $15 \mathrm{~km}$ a leste do depósito de Au-Pd-Pt de Serra Pelada.

\section{DADOS UTILIZADOS}

Os dados aeromagnéticos foram coletados ao longo de linhas de voo de direção NS, com espaçamento de $250 \mathrm{~m}$ entre os pontos. As linhas de controle tiveram direção EW, com espaçamento de $6000 \mathrm{~m}$ entre os pontos. Foi utilizado um aeromagnetômetro CS2 de vapor de césio, com sensibilidade de 0,01 nT e frequência de amostragem de $10 \mathrm{~Hz}$ em ciclo contínuo acoplado à cauda da aeronave, com um compensador dos efeitos da linha de voo e um sistema eletromagnético GEOTEM III Ltda. (GEOterrex Transient ElectroMagnetic system). 0 posicionamento foi efetuado por GPS da Trimble, modelo TANS II, com precisão aproximada entre 05 e $10 \mathrm{~m}$. A altura de voo foi fixada em $120 \mathrm{~m}$ sobre 0 terreno, tendo sido controlada por um radar altímetro Terra, modelo TRA. 0 levantamento aerogeofísico foi contratado pela Vale e conduzido pela Geoterrex-Dighem em março de 1999.

A redução de dados envolveu a etapa de pré-processamento, consistindo na eliminação da informação espúria, remoção do IGRF (International Geomagnetic Reference Field), interpolação dos dados e micronivelamento. A avaliação e eliminação de rú́dos na fase de pré-processamento foram baseadas na análise dos mapas e perfis das linhas de voo para identificação de dados espúrios.

Para 0 cálculo do campo magnético anômalo, efetuou-se a remoção da contribuição referente ao campo magnético principal, utilizando para isso o modelo IGRF de 1995 (Barton et al., 1996). Posteriormente, foi realizada a interpolação dos dados em uma malha regular. Dentre os algoritmos de interpolação testados (método da curvatura mínima e bidirecional), o que ofereceu 0 melhor resultado, depois de parametrizado adequadamente, foi 0 método da curvatura mínima (Briggs, 1974). 0 espaçamento entre os pontos da grade de dados foi de $62,5 \mathrm{~m}$ (1/4 do espaçamento entre as linhas de voo).

0 micronivelamento foi aplicado na etapa final de pré-processamento e serviu para corrigir imperfeições no nivelamento convencional dos dados ao longo das linhas de voo, as quais eram perceptíveis na malha obtida com o procedimento prévio. Esta 


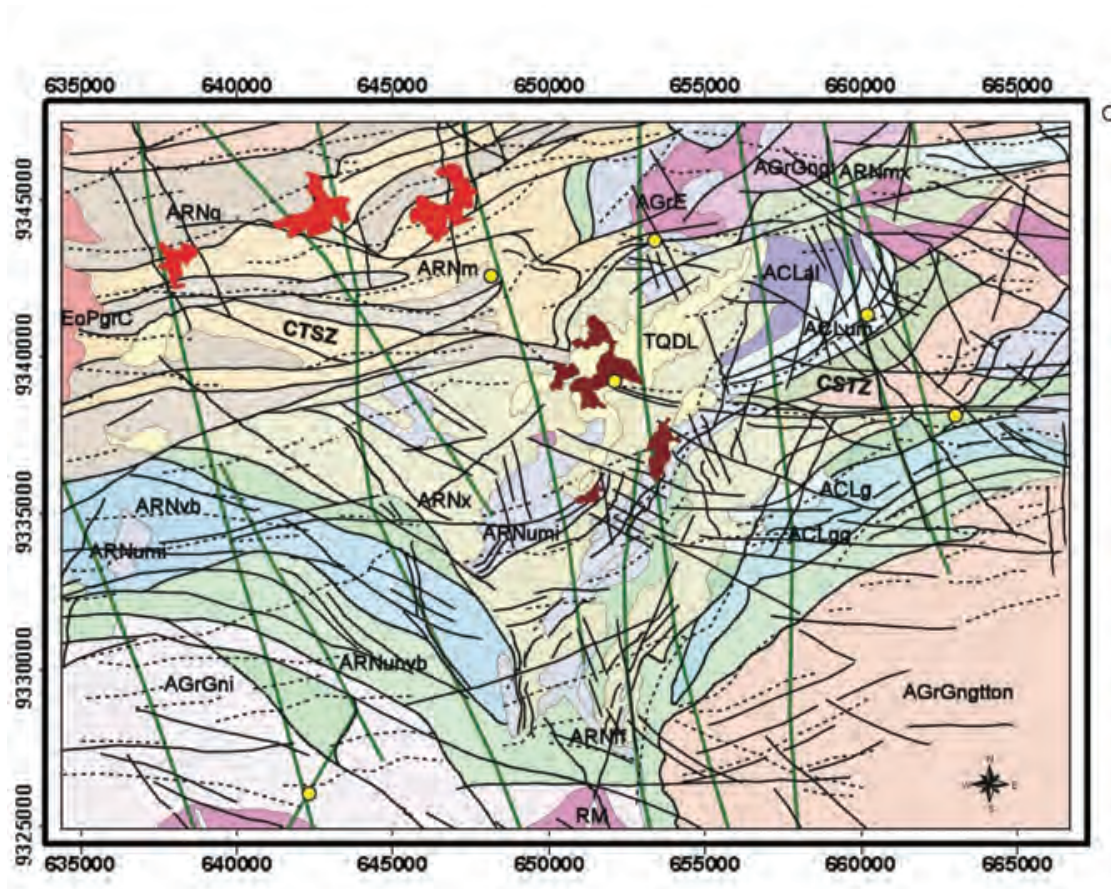

\section{LEGENDA \\ Eixos Magnéticos Anômalos $\checkmark$ Estruturas}

CTSZ - Zona de Cisalhamento Transcorrente Cinzento Coluna Litoestatigráfica

Quatemário/Cobertura

TQDL - Cobertura Lateritica

TQDL - Formaçes de Ferro

TQDL-Latossolo

$\square$ EoPgGb - Diques Gabróico Granofiricos

EoPgrC - Granito Cigano

Arqueano/Grupo Rio Novo

ARFm - Metapelitos - Metassiltitos

$\square$ ARFq - Quartzitos

Arqueano/Granito

$\square$ AGrE - Granito Estrela

Arqueano/Complexos Máficas-Ultramáficas

$\square$ ACLgg - Gabros de Grâo Grosseiro

$\square$ ACLg - Gabros

ACLal - Anortositos e Leuco-Gabros

$\square$ ACLum - Piroxenitos, Peridotitos e Dunitos

Arqueano/Grupa Rio Novo

ARNff - Formaçoes de Ferro

$\square$ ARNmx - Máficas e Xistos

$\square$ ARNumi - Ultramáficas năo-dinferenciado

ARNunvb - Máficas e Vulcânicas Básicas

ARNvb - Vulcânicas Básicas

ARNx - Sericita- Clorita - Talco Xistos

Arqueano/Embasamento Xingu

$\checkmark$ AGrGngt - Granitos Tonaliticos e Gnaisses

AGrGngtton - Tonalitos e Granitos Plutonicos

AgrGni - Granitos não-diferenciados e Gnaisses

Figura 2 - Mapa geológico da área de Serra Leste, com espacialização dos depósitos minerais compreendidos na área de estudo (Souza Filho et al., 2007).

etapa foi realizada utilizando o método descrito em Leite \& Souza Filho (2009b). Como resultado, foi obtido o campo anômalo micronivelado (Fig. 3), utilizado para aplicar as transformações lineares do campo magnético e métodos de estimativa de profundidades. Através deste produto foi possível verificar a tendência de alongamento das anomalias dipolares preferencialmente segundo a direção NE.

\section{MÉTODOS}

\section{Deconvolução de Euler}

0 método da Deconvolução de Euler (Reid et al., 1990), diferentemente dos outros métodos, não assume como premissa um modelo geológico particular, sendo necessário testar diferentes modelos, de forma a adequar a fonte ao modelo real.

A equação de homogeneidade de Euler é escrita na forma

$$
\begin{gathered}
\left(X-X_{0}\right)\left(\frac{\partial T}{\partial x}\right)+\left(Y-Y_{0}\right)\left(\frac{\partial T}{\partial y}\right) \\
+\left(Z-Z_{0}\right)\left(\frac{\partial T}{\partial z}\right)=N(B-T),
\end{gathered}
$$

onde $X_{0}, Y_{0}$ e $Z_{0}$ referem-se à posição da fonte magnética em relação ao campo total $T$ na posição $X, Y, Z$ no ponto de medida do campo magnético. 0 valor regional do campo total $T$ é 0 valor $B$ da equação. Expandindo os termos da Eq. (1) e considerando $n$ pontos com valores do campo magnético, monta-se um sistema de equações lineares do tipo

$$
\mathbf{A m}=\mathbf{c},
$$

sendo $\mathbf{m}=\left[X_{0} Y_{0} Z_{0} B\right]^{T}$ o vetor de parâmetros desconhecidos. Explicitamente, 0 sistema é escrito na forma

$$
\begin{gathered}
\left(\begin{array}{cccc}
\partial T_{1} / \partial X & \partial T_{1} / \partial Y & \partial T_{1} / \partial Z & N \\
\vdots & \vdots & \vdots & \vdots \\
\partial T_{n} / \partial X & \partial T_{n} / \partial Y & \partial T_{n} / \partial Z & N
\end{array}\right)\left(\begin{array}{c}
X_{0} \\
Y_{0} \\
Z_{0} \\
B
\end{array}\right)= \\
\left(\begin{array}{c}
X_{1} \partial T_{1} / \partial X+Y_{1} \partial T_{1} / \partial Y+Z_{1} \partial T_{1} / \partial Z+N T_{1} \\
\vdots \\
X_{n} \partial T_{n} / \partial X+Y_{n} \partial T_{n} / \partial Y+Z_{n} \partial T_{n} / \partial Z+N T_{n}
\end{array}\right) .
\end{gathered}
$$

Com relação ao procedimento computacional, a Deconvolução de Euler estima as coordenadas de localização da fonte anômala $\left(X_{0}, Y_{0}, Z_{0}\right)$ e 0 nível de base $B$ resolvendo 0 sistema linear de $n$ equações (Eq. 3), nestas 4 incógnitas, via método dos mínimos quadrados, 0 que resulta na seguinte solução:

$$
\mathbf{m}=\left(\mathbf{A}^{T} \mathbf{A}\right)^{-1} \mathbf{A}^{T} \mathbf{c} .
$$




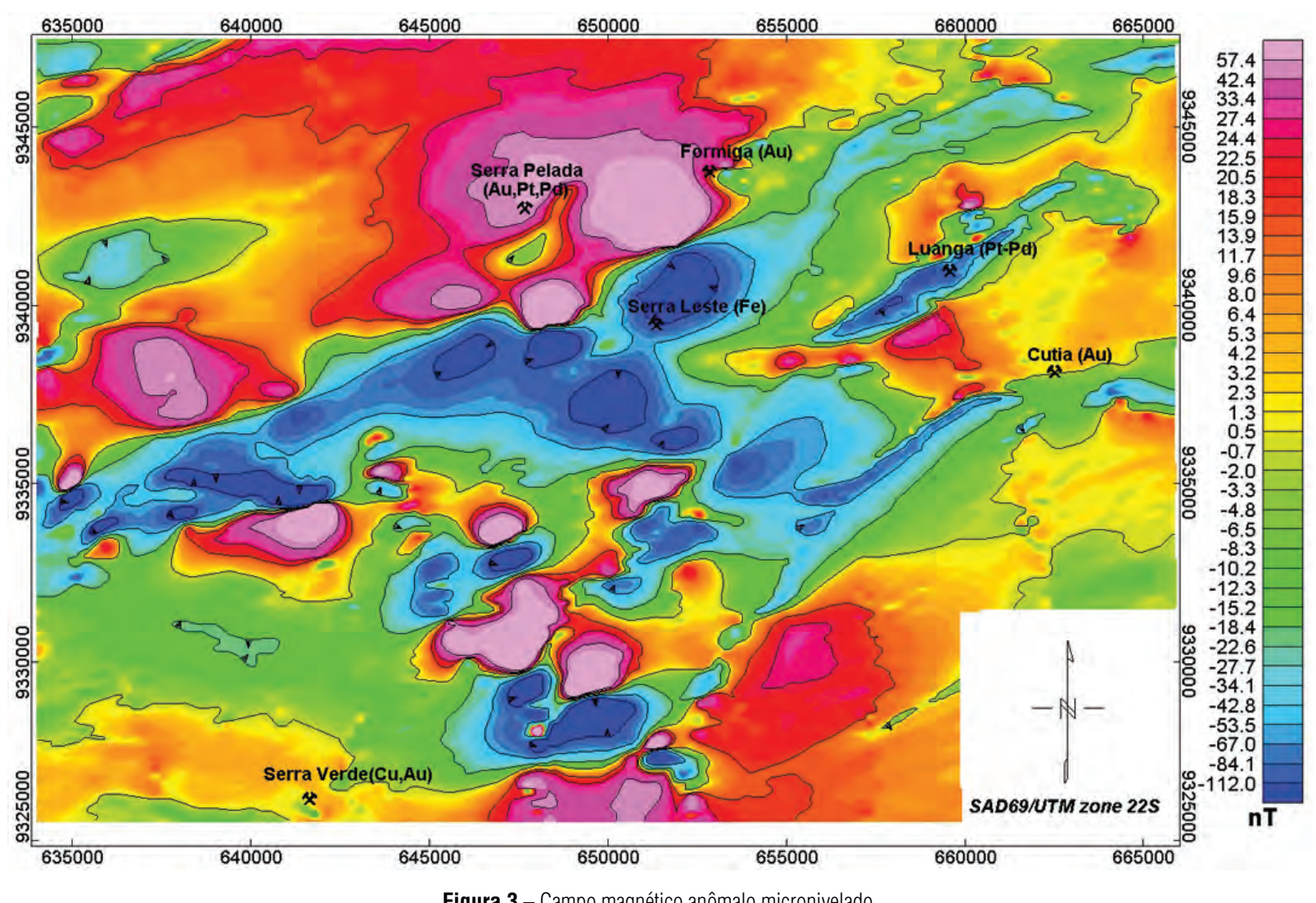

Figura 3 - Campo magnético anômalo micronivelado.

0 grau de homogeneidade $N$ é interpretado como sendo um índice estrutural, o qual representa a taxa de decaimento da anomalia com a distância entre a fonte e o ponto de medida, sendo um indicador referente à forma geométrica da fonte anômala (Tab. 1). 0 método utiliza a sobreposição de janelas móveis e produz uma solução para cada janela, de modo que o número total de soluções se aproxime do número de pontos da grade. A incerteza na solução pode aumentar devido aos seguintes fatores: (i) a janela inclui gradientes muito pequenos; (ii) os gradientes são provenientes de várias fontes magnéticas; (iii) a grade de dados é de baixa resolução; ou (iv) o nível de ruído dos dados é muito alto. Se o tamanho da janela for escolhido sem um critério apropriado, algumas estruturas (e.g., contatos) podem ser envolvidas por soluções provenientes de fontes adjacentes e interferentes, mascarando as soluções associadas à anomalia magnética no ponto de cálculo.

Para a estimativa do tamanho de janela, foi calculado um tamanho médio para dez anomalias da grade, 0 qual foi dividido pelo espaçamento da grade de dados. Teoricamente, existem razões para se manter a janela o menor possível, pois evita a inclusão de soluções adicionais. Por outro lado, anomalias provenientes de fontes profundas são de representação precária em janelas de pequena dimensão, 0 que resulta na subestimativa das profundidades e posições dessas fontes (Reid et al., 1990).

\section{Sinal Analítico}

0 Sinal Analítico ou envelope de energia das anomalias magnéticas baseia-se em um conjunto de métodos semi-automáticos aplicados às derivadas verticais e horizontais do campo magnético, sendo independente dos parâmetros do campo magnético terrestre e da direção de magnetização da fonte (Nabighian, 1972; Nabighian, 1974). Este fato torna-se uma grande vantagem devida à exclusão da necessidade de redução ao polo e conhecimento prévio das características magnéticas das fontes (Roest et al., 1992). Sendo assim, os picos anômalos são projetados diretamente sobre os contatos. Isto é muito importante, especialmente em áreas onde a magnetização remanescente é desconhecida. Contudo, os contatos necessitam ser isolados e bidimensionais (Roest et al., 1992).

Definindo $\hat{x}, \hat{y}$ e $\hat{z}$ como vetores unitários nas direções $-x,-y$ e $-z$, respectivamente, o Sinal Analítico do campo 
Tabela 1 - Relação entre 0 índice estrutural e a forma geométrica da fonte magnética anômala.

\begin{tabular}{|c|c|}
\hline Índice estrutural & Forma geométrica da fonte anômala \\
\hline$N=0$ ou $\sim 0$ & Contatos ou falhas com altos deslocamentos \\
\hline$N=0,5$ & Contatos ou falhas com moderados deslocamentos \\
\hline$N=1,0$ & Diques, soleiras ou falhas com pequenos deslocamentos \\
\hline$N=2,0$ & Cilindros horizontais ou verticais \\
\hline$N=3,0$ & Esferas ou dipolos magnéticos \\
\hline
\end{tabular}

potencial anômalo $M$ pode ser descrito como:

$$
A(x, y)=\left(\frac{\partial M}{\partial x} \hat{x}+\frac{\partial M}{\partial y} \hat{y}+i \frac{\partial M}{\partial z} z\right) .
$$

A amplitude do Sinal Analítico é dada por:

$$
|A(x, y)|=\sqrt{\left(\frac{\partial M}{\partial x}\right)^{2}+\left(\frac{\partial M}{\partial y}\right)^{2}+\left(\frac{\partial M}{\partial z}\right)^{2}} .
$$

Desde que a amplitude do Sinal Analítico seja definida sobre contrastes magnéticos, esta pode ser utilizada para encontrar a localização horizontal e profundidades das fontes magnéticas.

0 primeiro passo compreende o cálculo da grade da amplitude do Sinal Analítico a partir da grade das anomalias magnéticas. Os gradientes do campo anômalo nas duas direções horizontais ortogonais, $-x \mathrm{e}-y$, são calculados usando uma aproximação de diferença finita. Uma janela $3 \times 3$ passa por cada ponto da grade, sendo calculadas as diferenças médias entre os pontos da grade nas direções $-x$ e $-y$. A amplitude do Sinal Analítico é calculada para cada ponto da grade usando a Eq. 6 .

0 segundo passo tem por objetivo a localização de picos na amplitude do Sinal Analítico. 0 valor dos picos é determinado através da inserção de uma janela $3 \times 3$ com a nova grade criada e identificação do máximo local. Cada intersecção da grade, exceto para as linhas e colunas nas margens, é comparada com as suas oito intersecções vizinhas em quatro direções (ao longo da linha, coluna e ambas as diagonais) para encontrar qualquer máximo local presente. Se um máximo local é detectado, é mais fácil encontrar uma localização horizontal e uma magnitude do máximo precisa através da interpolação de um polinômio de segunda ordem pelo trio de pontos (Phillips, 2001).

0 terceiro consiste no cálculo das profundidades dos contatos após a localização dos picos na amplitude do Sinal Analítico. Phillips (1997) utiliza uma aproximação similar para encontrar 0 máximo, mas adota uma janela $5 \times 5$ para localizar ambos os picos na amplitude do Sinal Analítico e as suas direções de strike. Quando 0 algoritmo encontra 0 azimute do perfil através do máximo, este é assumido como perpendicular ao strike de uma anomalia linear. Assim que as cristas e suas direções de strike são conhecidas, a grade pode ser usada para determinar a profundidade do contato. Isso é feito através do método dos mínimos quadrados, aplicado à curva teórica da amplitude do Sinal Analítico bidimensional sobre um contato (Phillips, 2001). Esta curva teórica é dada por

$$
|A(x)| \propto \frac{\alpha}{\sqrt{x^{2}+d^{2}}},
$$

onde $x$ é a distância horizontal ao contato; $d$ a profundidade ao topo do contato; e $\alpha$ é produto do contraste de susceptibilidade magnética ao longo do contato magnético, da inclinação e força do campo magnético terrestre, e 0 ângulo entre o norte magnético e 0 eixo positivo $-x$ (Nabighian, 1972).

Os aspectos importantes a serem levados em conta na aplicação do método do Sinal Analítico ao campo anômalo são: (i) a amplitude do Sinal Analítico varia com a magnetização efetiva, levando a problemas quando o mesmo é utilizado em regiões próximas ao equador magnético; (ii) quando o Sinal Analítico é resultado de fontes interferentes ou profundas, sua análise torna-se mais complexa, sendo necessário um desenvolvimento de realce do Sinal Analítico, de forma a reduzir este efeito (Hsu et al., 1996); (iii) o Sinal Analítico sobre estruturas que se interceptam formando um ângulo agudo é de difícil análise devido à combinação não linear dos sinais; (iv) como o Sinal Analítico é calculado a partir da derivada do campo anômalo, os erros provocados pelo posicionamento do avião e ruídos em geral são realçados (Roest et al., 1992).

\section{Número de Onda Local}

0 Número de Onda Local provém do método designado SPI ${ }^{\top \mathrm{M}}$ (Source Parameter Imaging; Thurston \& Smith, 1997), que estende a teoria do Sinal Analítico através do cálculo de três atributos complexos a partir dos quais alguns parâmetros das fontes podem ser calculados. No caso de dados magnéticos, estes atributos incluem a amplitude local, fase local e o Número de Onda Local. 
Admitindo uma fonte bidimensional, a partir da definição do Sinal Analítico e da fase local do Sinal Analítico (Reid et al., 1990), deduz-se a frequência local como sendo o grau de mudança da fase local em relação à coordenada $x$, expressa por

$$
f=\frac{1}{2 \pi} \frac{\partial}{\partial x} \tan ^{-1}\left[\frac{\partial M}{\partial z} / \frac{\partial M}{\partial x}\right],
$$

onde $z$ e $x$ são coordenadas cartesianas para a direção vertical e a direção perpendicular ao strike, respectivamente. Na análise do campo potencial, é conveniente usar o Número de Onda Local, definido por $k$, em vez de $f$, como sendo

$$
k=2 \pi f .
$$

Efetuando a substituiç̧ão, o Número de Onda Local pode ser expresso como

$$
k=\frac{\partial\left(\tan ^{-1}\left[\frac{\partial M}{\partial z} / \frac{\partial M}{\partial x}\right]\right)}{\partial x} .
$$

Os atributos utilizados na localização de contatos e profundidades são definidos a partir das expressões para 0 gradiente vertical e horizontal para um contato inclinado:

$$
\begin{gathered}
\frac{\partial M}{\partial z}=2 K F c \sin d \\
\times \frac{x \cos (2 I-d-90)-h \sin (2 I-d-90)}{h^{2}+x^{2}} ; \mathrm{e} \\
\frac{\partial M}{\partial x}=2 K F c \sin d \\
\times \frac{h \cos (2 I-d-90)-x \sin (2 I-d-90)}{h^{2}+x^{2}}
\end{gathered}
$$

onde $K$ é 0 contraste de susceptibilidade no contato; $F$ a magnitude do campo magnético terrestre; $c=1-\cos ^{2} i \sin ^{2} \alpha$; $\alpha 0$ ângulo entre 0 eixo positivo de $x$ e 0 norte magnético; $i$ a inclinação do campo geomagnético; $\tan I=\tan i / \cos \alpha ; d$ a inclinação, medida do eixo positivo de $x$; e $h$ a profundidade de topo do contato. Substituindo as Eqs. 11 e 12 na expressão do Número de Onda Local têm-se que a curva teórica do Número de Onda Local bidimensional sobre um contato é dada por

$$
k=\frac{h}{h^{2}+x^{2}} .
$$

A origem do sistema, definida para $x=0$, está diretamente sobre o contato. Desta forma, fica evidente que os máximos do Número de Onda Local são independentes da direção de magnetização da fonte. Sendo assim, os picos representam os limites das fontes, que se encontram em valores de $x=0$. Nestes pontos pode-se calcular a profundidade local por

$$
h=\frac{1}{k} \text {. }
$$

Ou seja, o Número de Onda Local é inversamente proporcional à profundidade de topo dos contatos. Assim, é plausível concluir que fontes muito profundas associam-se a baixos valores do Número de Onda Local, assumindo-se um ponto de observação sobre o contato $(x=0)$. É possível ainda, com este método, estimar o mergulho local, a inclinação do contato e o contraste de susceptibilidade magnética, admitindo-se a ausência de magnetização remanescente (Thurston \& Smith, 1997). Porém, esses parâmetros não foram analisados neste trabalho.

0 Número de Onda Local, assim como o Sinal Analítico, gera picos sobre os contatos magnéticos e é independente da direção do campo magnético regional, da magnetização da fonte e do mergulho do contato. Na dedução da profundidade, mergulho e susceptibilidade magnética local, admite-se que não há interferência de anomalias adjacentes. 0 procedimento de cálculo do Número de Onda Local envolve duas vantagens: (i) elimina os erros causados pelas linhas de voo que não estão perpendiculares à direção de strike; e (ii) não há dependência na escolha de tamanho da janela móvel, ao contrário do método da Deconvolução de Euler (Thurston \& Smith, 1997).

\section{RESULTADOS}

0 programa computacional OASIS Montaj ${ }^{\mathrm{TM}}$ (Geosoft, 2006) foi utilizado para calcular as soluções pelo método da Deconvolução de Euler. Os métodos do Sinal Analítico e Número de Onda Local foram aplicados com 0 auxílio do Potential Field Software do USGS (United States Geological Survey) (Phillips, 1997). A altitude de voo foi somada aos valores de profundidade para todos os métodos. Portanto, os valores apresentados referem-se à superfície topográfica.

$\mathrm{Na}$ área de estudo predominam estruturas geológicas como contatos e falhas. Nestes casos, os índices estruturais adequados para representação das fontes magnéticas em profundidade variam de 0 até 1 (e.g. Reid et al., 1990, Barbosa \& Silva, 2005). Em particular, foram estimadas profundidades pelo método de Euler utilizando índices estruturais $N=0,01 ; 0,25 ; 0,5 ; 0,75$; e 1,0. Como exemplo, a Figura 4 mostra os histogramas e parâmetros estatísticos referentes às soluções obtidas com este método para $N=0,01 ; 0,5$; e 1,0 . As Figuras 5,6 e 7 mostram a distribuição espacial e em profundidade das soluções. 0 tamanho da janela móvel utilizada foi de $20 \times 20$ (i.e. $1250 \times$ 

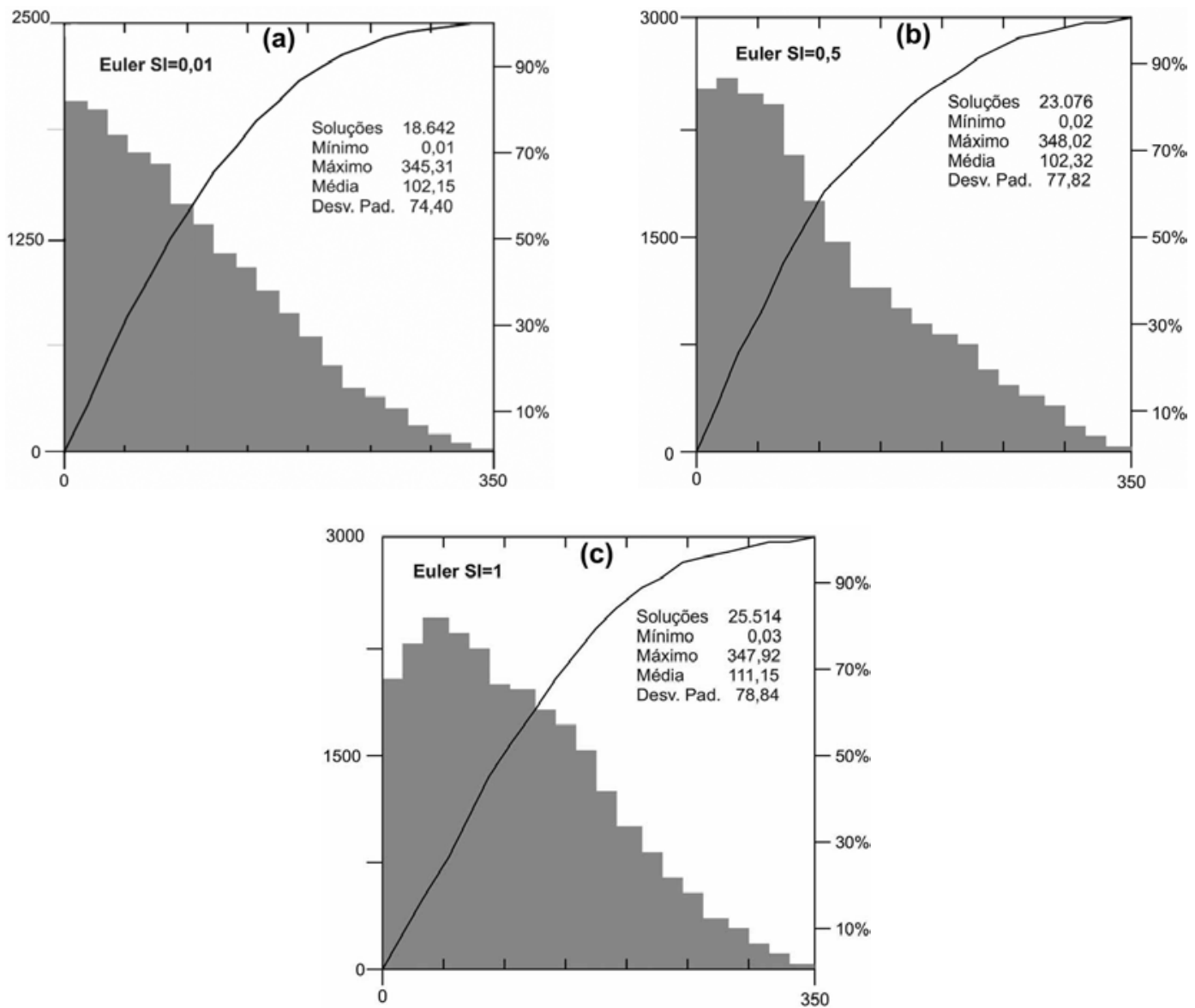

Figura 4 - Histogramas do número de soluções em função da profundidade, em metros, para o método da Deconvolução de Euler.

1250 m) Os critérios para aceitação das soluções foram: (i) erro menor ou igual a 10\% em relação à profundidade estimada; (ii) distância horizontal da fonte magnética menor ou igual à metade do tamanho da janela móvel (625 m). Utilizando este critério para limitar a distância horizontal, admitimos que a posição $(X, Y)$ da fonte magnética está situada dentro da janela móvel, uma vez que o ponto de medida corresponde ao centro desta janela.

Os histogramas das distribuições de profundidades estimadas pelos métodos do Sinal Analítico e Número de Onda Local são apresentados na Figura 8, junto com seus principais parâmetros estatísticos. As distribuiçõos espacial e em profundidade das soluções obtidas pela aplicação destes dois métodos podem ser observadas nas Figuras 9 e 10.

De uma maneira geral, a distribuição de soluções é bastante similar para todos os métodos. Nota-se que a profundidade média estimada para as fontes magnéticas é muito próxima de $100 \mathrm{~m}$. Entretanto, os métodos do Sinal Analítico e Número de Onda
Local forneceram profundidades máximas maiores, refletindo em maiores desvios padrões (Figs. 4 e 5 ).

No caso das soluções do método de Euler, 0 erro médio associado à profundidade decai com o aumento do valor do índice estrutural. Porém, ressalta-se que a variação é pequena, da ordem de 3\% (Tab. 2). 0 método do Número de Onda Local forneceu o maior erro médio (10,67\%) associado ao valor estimado de profundidade. Analisando os histogramas das Figuras 4 e 5, é notável também que os métodos do Sinal Analítico e do Número de Onda Local forneceram menos soluções e as distribuições são mais esparsas.

Para cada índice estrutural, foi calculado o coeficiente de correlação entre $B$ e $T$, definidos na Equação 1 (Tab. 3). Neste caso, é importante enfatizar que no lugar de $T$ foi 0 utilizado 0 campo anômalo micronivelado $M$. De acordo com Barbosa et al. (1999), o menor coeficiente de correlação fornece 0 índice estrutural correto. Esta conclusão foi embasada teoricamente e empiricamente naquele trabalho, através de exemplos com da- 


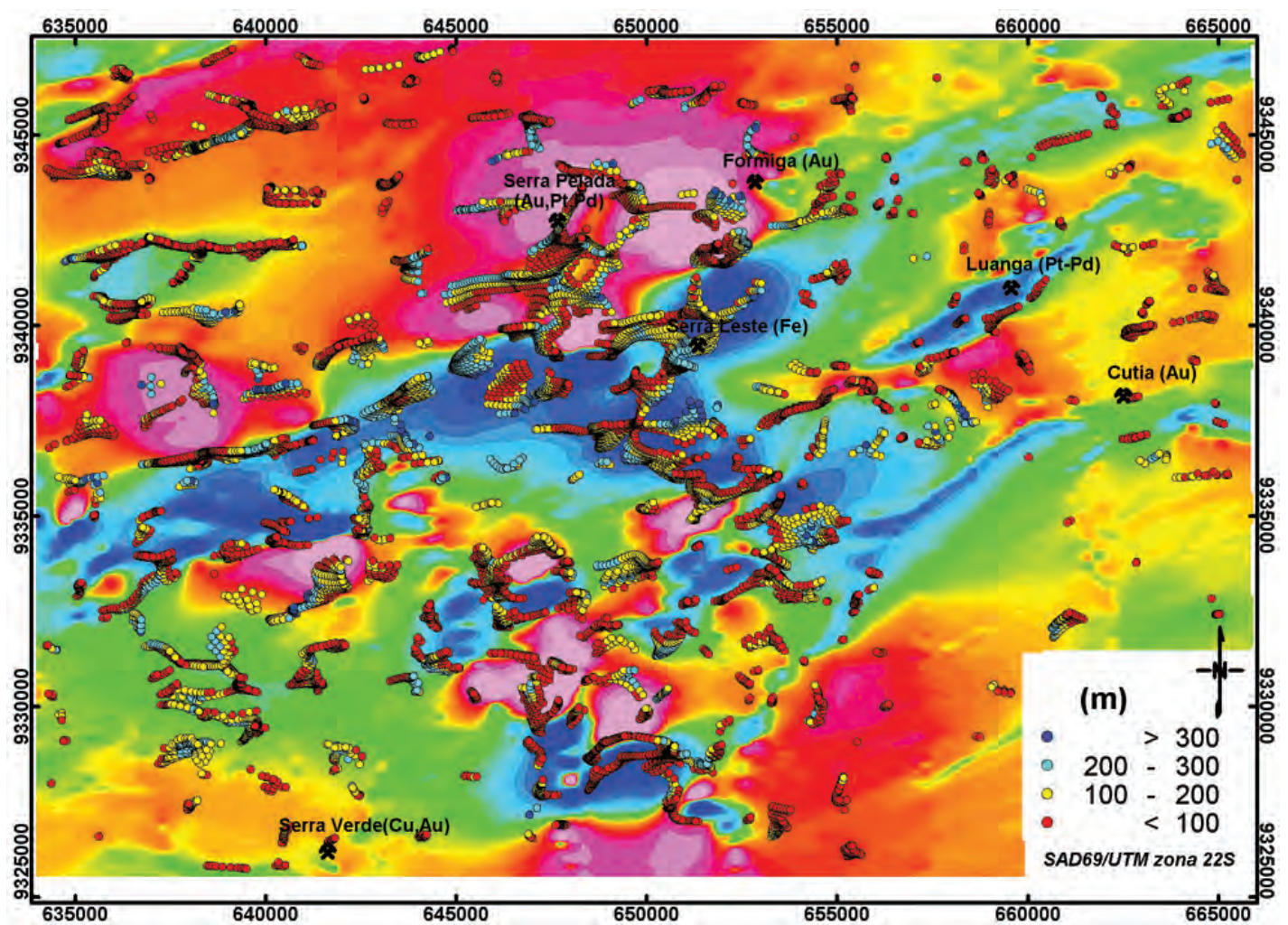

Figura 5 - Mapa de soluções da Deconvolução de Euler para um índice estrutural de 0,01.

dos sintéticos para cilindros horizontais e contatos, além de dados reais. Para os dados aqui utilizados, o menor coeficiente de correlação ocorre para índice estrutural 0,01. Isso indica que este é o índice estrutural correto para modelar a maioria das fontes magnéticas dentro da área de estudo. Este índice foi utilizado no lugar do índice estrutural nulo, para possibilitar a estimativa do nível de base $B$ e posterior cálculo do coeficiente de correlação.

Adicionalmente, observou-se também a dispersão das soluções no mapa, sendo que 0 agrupamento das soluções de forma menos dispersa deve refletir o índice estrutural correto para aquela região (Reid et al., 1990). Bons agrupamentos foram obtidos para todos os índices estruturais utilizados, o que comprova a adequada seleção prévia dos índices estruturais no intervalo entre 0 e 1 .

\section{DISCUSSÕES}

A distribuição espacial das soluções é claramente mais correlacionada com as estruturas e contatos geológicos no caso do método de Euler, quando comparada com as soluções obtidas com os outros dois métodos (Figs. 6-10). De acordo com to- dos os resultados, a maioria das fontes magnéticas encontra-se abaixo de $100 \mathrm{~m}$ de profundidade.

Tabela 2 - Erro padrão médio em porcentagem e soma aritmética do erro referente à distribuição das soluções em profundidade para os três métodos estudados.

\begin{tabular}{|c|c|c|}
\hline Método & $\begin{array}{c}\text { Erro médio } \\
(\%)\end{array}$ & $\begin{array}{c}\text { Soma aritmética } \\
\text { do erro }\end{array}$ \\
\hline Euler $(N=0,01)$ & $6,36 \pm 2,14$ & $163.792,18$ \\
\hline Euler $(N=0,5)$ & $6,28 \pm 2,18$ & $135.996,26$ \\
\hline Euler $(N=1,0)$ & $5,91 \pm 2,14$ & $179.265,43$ \\
\hline Sinal Analítico & $10,28 \pm 3,11$ & $16.966,22$ \\
\hline Número de Onda Local & $10,67 \pm 2,99$ & $5.133,34$ \\
\hline
\end{tabular}

Tabela 3 - Coeficientes de correlação entre o nível de base $B$ e 0 campo magnético anômalo $M$ para cada índice estrutural $N$.

\begin{tabular}{|c|c|}
\hline Índice estrutural $(N)$ & Coeficiente de correlação $(r)$ \\
\hline 0,01 & $-0,84$ \\
\hline 0,25 & $-0,72$ \\
\hline 0,50 & $-0,52$ \\
\hline 0,75 & $-0,26$ \\
\hline 1,00 & $+0,04$ \\
\hline
\end{tabular}




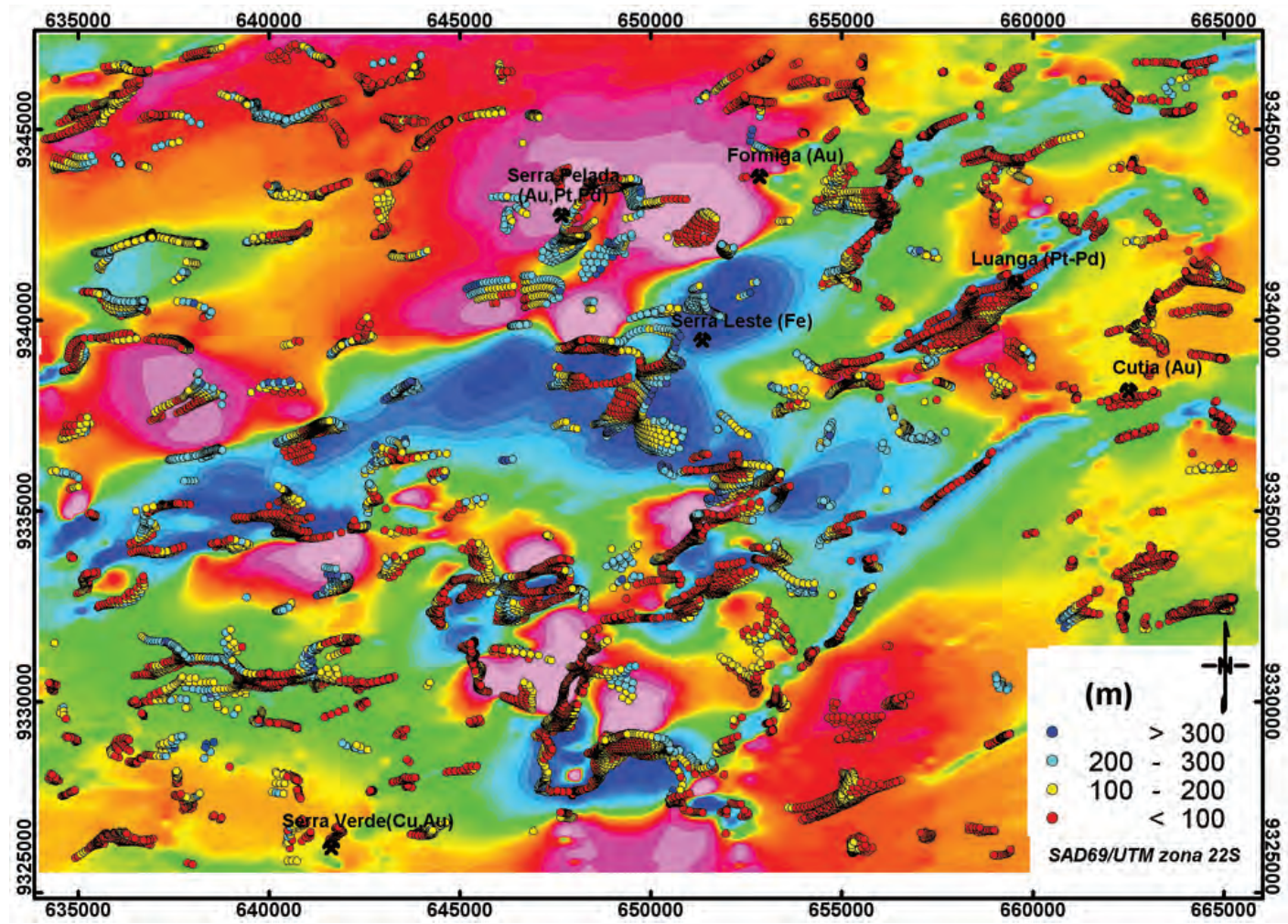

Figura 6 - Mapa de soluções da Deconvolução de Euler para um índice estrutural de 0,5.

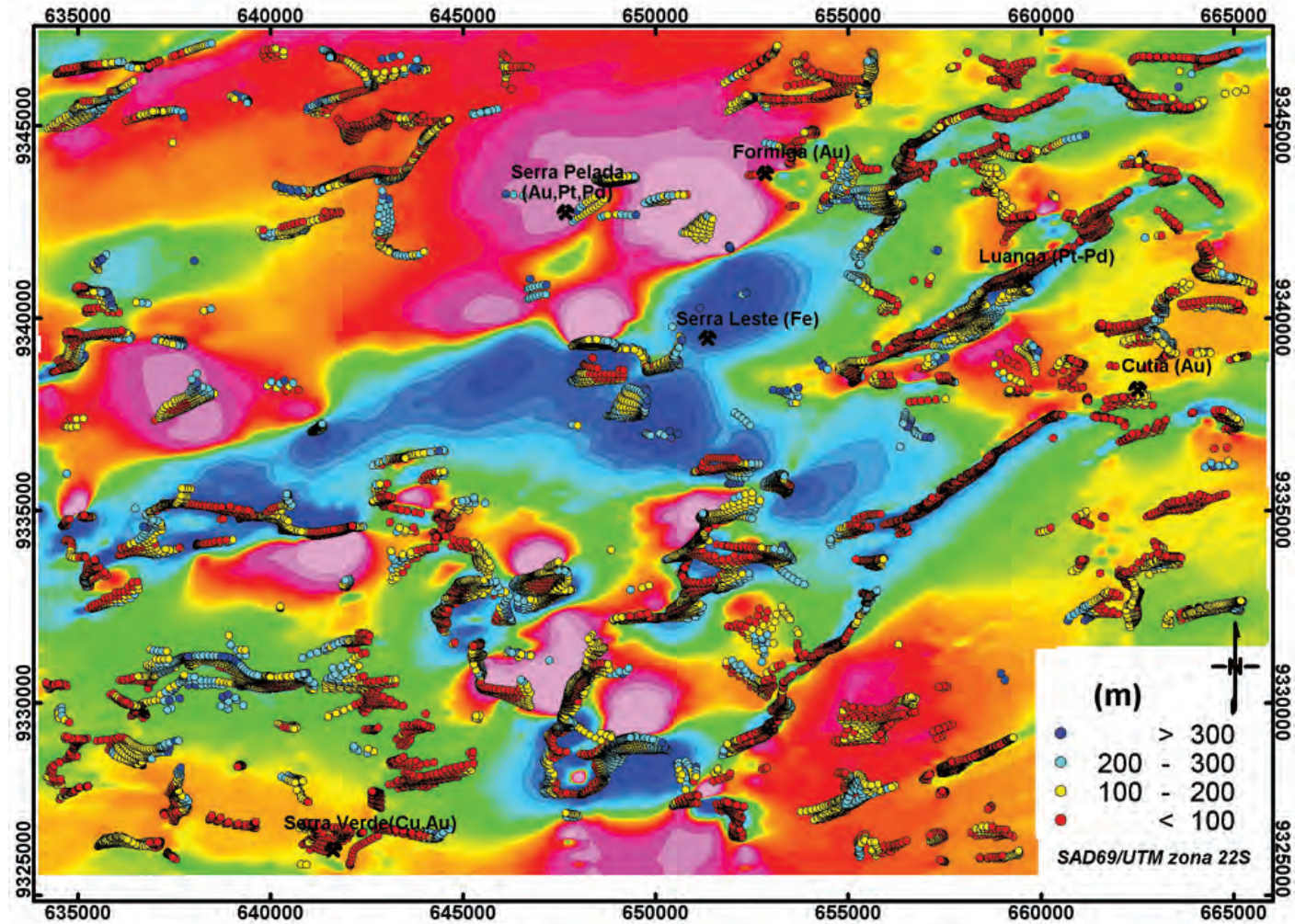

Figura 7 - Mapa de soluções da Deconvolução de Euler para um índice estrutural de 1,0. 

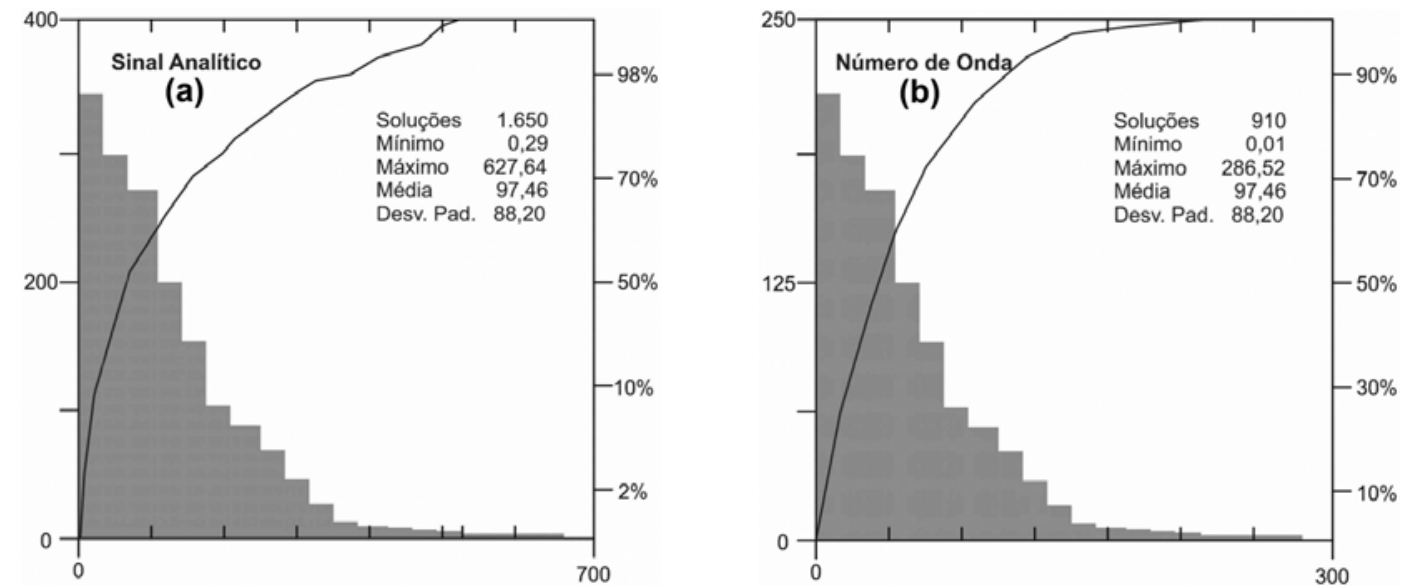

Figura 8 - Histogramas do número de soluções em função da profundidade, em metros, para os métodos do Sinal Analítico e Número de Onda Local.

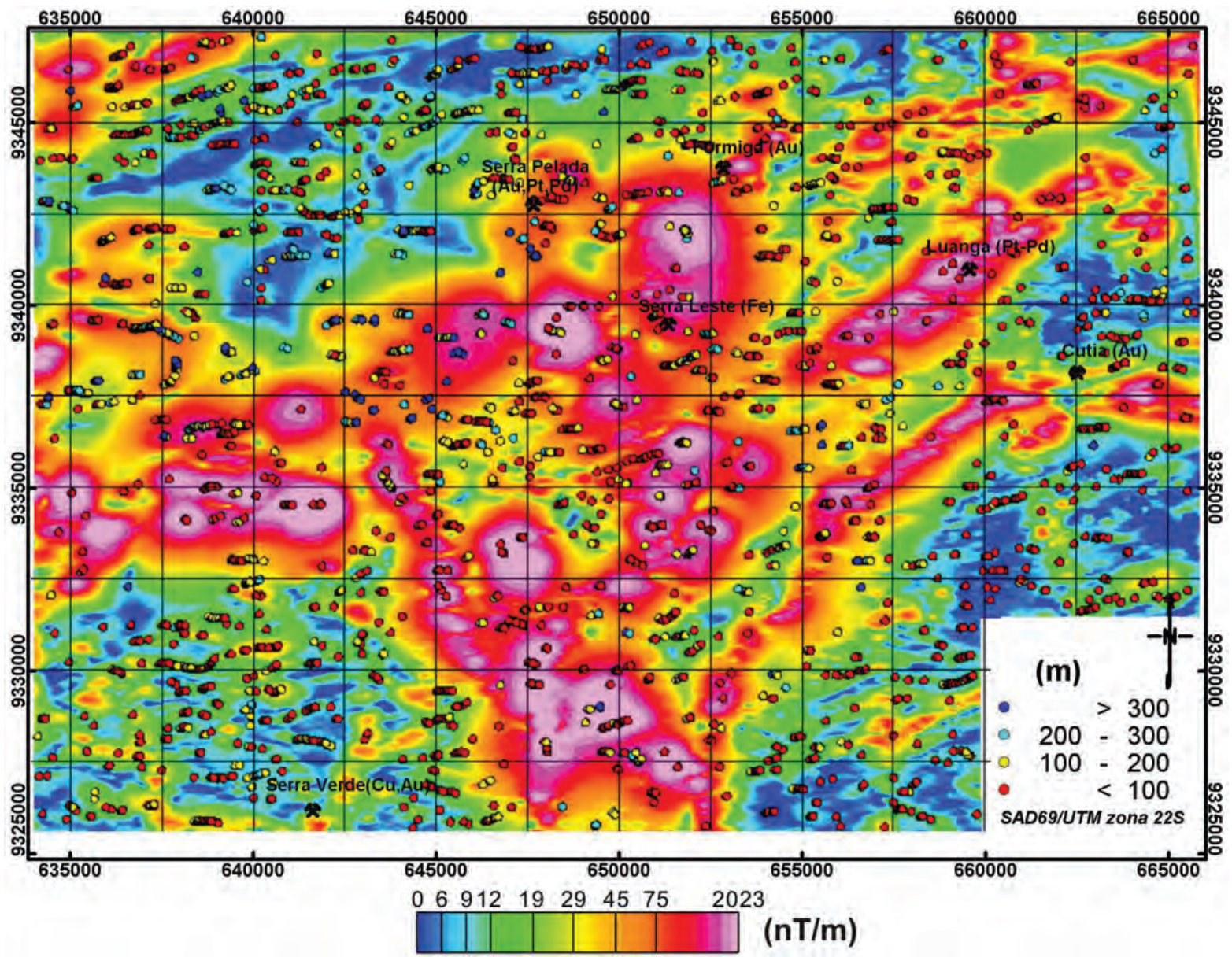

Figura 9 - Mapa de soluções do Sinal Analítico.

As estruturas de direção NE-SW e E-W do Grupo Rio Fresco (ARFq e ARFm) são melhores mapeadas com índices estruturais entre 0,01 e 0,5. A porção leste do STC é vista como um trend linear de soluções de profundidades menores do que $100 \mathrm{~m}$ para $N=0,01$ e levemente observada no mapa de $N=0,5$. Em particular, uma estrutura NE-SW que corta os xistos (ARNx) e vulcânicas 


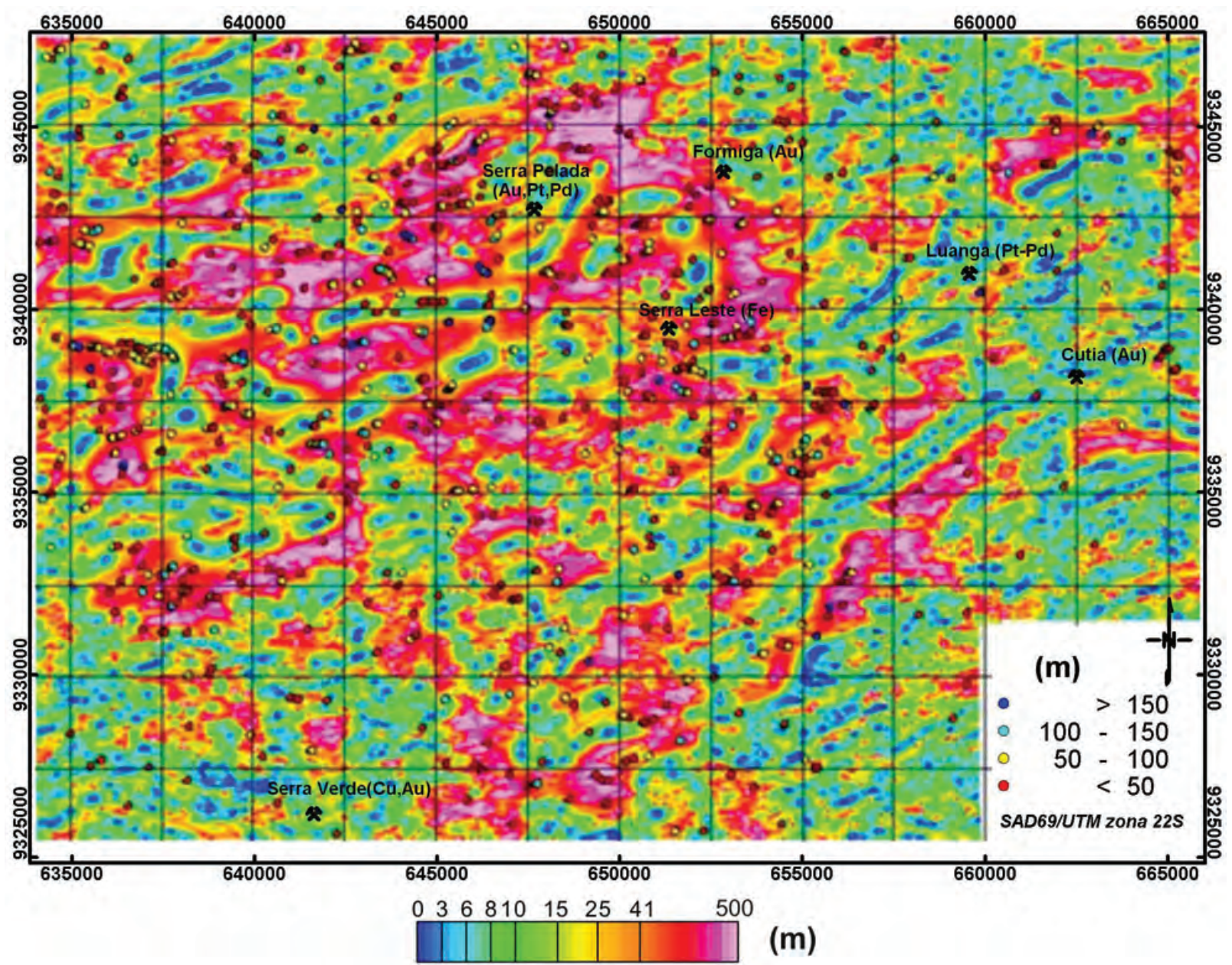

Figura 10 - Mapa de soluções do Número de Onda Local. A escala de cores representa o inverso do Número de Onda Local.

básicas (ARNvb) do Grupo Rio Novo é bem delineada quando $N=0,01$ (região central-leste da área de estudo). Neste caso, nota-se que a estrutura mergulha em profundidade, passando de profundidades menores do que $100 \mathrm{~m}$ para até $300 \mathrm{~m}$. Duas grandes estruturas dentro do complexo máfico-ultramáfico de Luanga são representadas por nuvens de soluções menos dispersas para $N=1,0$.

0 depósito de Luanga (Pt-Pd) está associado a essas estruturas e, desta forma, estima-se que a profundidade da fonte magnética próxima a este depósito situe-se em torno de $50 \mathrm{~m}$ (Tab. 4). No caso do depósito de Serra Leste (Fe), a única solução obtida diretamente pelo método, i.e., sem interpolação, foi aquela pelo método de Euler para $N=0,01,0$ que resultou em uma profundidade de cerca de $182 \mathrm{~m}$. 0 depósito de Serra Pelada (Au, Pt, Pd) está posicionado sobre um trend mergulhante de direção NNE-SWW, com profundidades variando de 25 até
$270 \mathrm{~m}$. Particularmente sobre 0 depósito, a profundidade estimada com $N=0,01$ foi de $205,5 \mathrm{~m}$. Os outros métodos também forneceram profundidades superiores a $130 \mathrm{~m}$ para regiões nas vizinhanças deste depósito. No caso do depósito de Serra Verde ( $\mathrm{Cu}, \mathrm{Au}$ ), há poucas soluções confiáveis obtidas com os métodos do Sinal Analítico e Número de Onda Local. Desta forma, baseado nos resultados do método de Euler, estima-se que a profundidade da fonte magnética mais próxima deste depósito esteja em torno dos $60 \mathrm{~m}$. Na região do depósito de Serra Verde (Au), de acordo com o bom agrupamento de soluções para $N=0,5$ e $N=1,0$, os resultados sugerem que existem fontes a profundidades rasas $(\sim 30 \mathrm{~m})$ e fontes a maiores profundidades ( $\sim 110 \mathrm{~m})$. As profundidades maiores são corroboradas pelo vaIor estimado pelo Sinal Analítico. Para o depósito de Formiga (Au), não há soluções diretas confiáveis obtidas com $0 N=0,01$. Levando em conta os resultados para $N=0,5, N=1,0$ e para 0 
Tabela 4 - Estimativa em metros da profundidade da fonte magnética sobre os depósitos minerais na região de estudo. Valores marcados com asterisco indicam que foram obtidos através da média dos vizinhos mais próximos.

\begin{tabular}{|c|c|c|c|c|c|c|}
\hline Método & Serra Pelada & Formiga & Luanga & Serra Leste & Cutia & Serra Verde \\
\hline Euler $(N=0,01)$ & $205,48 \pm 11,51$ & $75,44 \pm 5,81^{*}$ & $25,93 \pm 1,04^{*}$ & $182,42 \pm 6,55$ & $4,83 \pm 0,51^{*}$ & $34,95 \pm 3,02^{*}$ \\
\hline Euler $(N=0,5)$ & $244,52 \pm 17,21^{*}$ & $45,19 \pm 3,01^{*}$ & $22,92 \pm 1,98$ & $337,19 \pm 10,65^{*}$ & $49,31 \pm 6,82$ & $26,96 \pm 2,43$ \\
\hline Euler $(N=1,0)$ & $300,27 \pm 21,23^{*}$ & $41,48 \pm 4,36^{*}$ & $55,19 \pm 3,02$ & $301,29 \pm 7,58^{*}$ & $148,36 \pm 21,26$ & $112,09 \pm 8,96$ \\
\hline Sinal Analítico & $130,01 \pm 13,05$ & $60,51 \pm 7,37$ & $25,10 \pm 2,59^{*}$ & $85,34 \pm 9,69$ & $36,00 \pm 2,82^{*}$ & $133,16 \pm 17,26^{*}$ \\
\hline Número de Onda Local & $151,00 \pm 10,63^{*}$ & $40,05 \pm 5,44^{*}$ & $15,77 \pm 1,29^{*}$ & $38,08 \pm 4,03$ & $22,39 \pm 2,73$ & $94,21 \pm 12,31^{*}$ \\
\hline
\end{tabular}

Número de Onda Local, estima-se uma profundidade entre 40 e $45 \mathrm{~m}$ para as fontes magnéticas neste caso. Porém, aparentemente, as estruturas no entorno do depósito não são marcadas por contrastes magnéticos significativos.

\section{CONCLUSÕES}

Neste trabalho foram avaliados comparativamente os resultados de estimativa de profundidades de fontes magnéticas por três métodos distintos: (i) Deconvolução de Euler; (ii) Sinal Analítico; e (iii) Número de Onda Local. A área de estudo compreendeu a região de Serra Leste, na Província Mineral de Carajás.

0 método de Euler forneceu estatisticamente o melhor conjunto de soluções (erro padrão médio igual a 6\%) e estas puderam ser interpretadas dentro do contexto geológico da área de estudo de forma mais objetiva. 0 maior erro padrão médio foi obtido com o método do Número de Onda Local (10,67\%) e este método forneceu o menor conjunto de soluções dentro do critério pré-estabelecido para aceitação das soluções. Muitas regiões dentro da área de estudo não tiveram valores de profundidades estimados por este método. 0 método do Sinal Analítico resultou em um mapa de soluções onde é possivel observar diversos trends lineares associados às estruturas geológicas, porém a correlação é menor do que aquela observada para os mapas das soluções de Euler.

Foi possível também estimar profundidades magnéticas pontuais relacionadas aos depósitos minerais presentes na área de estudo e conclui-se que a maioria encontra-se em profundidades de até $200 \mathrm{~m}$. 0 depósito de Serra Pelada (Au, Pt, Pd) está posicionado sobre um trend mergulhante de direção NNE-SSW, com profundidades magnéticas que aumentam de cerca de 25 até 270 $\mathrm{m}$, sendo que na posição do depósito a profundidade estimada é de $205 \mathrm{~m}$. Estima-se que a profundidade da fonte magnética mais próxima ao depósito de Serra Leste situe-se a cerca de 182 m. Para o depósito de Serra Verde (Au), os resultados sugerem fontes a profundidades rasas $(\sim 30 \mathrm{~m})$ e fontes a maiores profundidades ( $\sim 110 \mathrm{~m}$ ). 0 depósito de Luanga (Pt-Pd) está associado a estruturas magnéticas de direção NE-SW com profundidades em torno de $50 \mathrm{~m}$.

\section{AGRADECIMENTOS}

Os autores agradecem à Vale por ceder os dados aeromagnéticos utilizados neste trabalho. M.G. Correia agradece ao Departamento de Geociências da Universidade de Aveiro, Portugal, em especial ao professor Dr. Jorge Medina e ao professor Dr. Manuel João dos Senos Matias, por proporcionarem e acompanharem a sua estadia no Brasil durante a elaboração deste trabalho. E.P. Leite e C.R. Souza Filho agradecem à Fundação de Amparo à Pesquisa do Estado de São Paulo (FAPESP) pela bolsa de pósdoutorado (Proc. N. 05/04453-3) e pelo suporte financeiro (Proc. N. 03-09916-6), respectivamente.

\section{REFERÊNCIAS}

ABOUD E, SALEM A \& USHIJUMA K. 2003. Interpretation of aeromagnetic data of Gebel El-Zeit Area, Gulf of Suez, Egypt Using Magnetic Gradient Techniques. Memoirs of the Faculty of Engineering, Kyushu University, SEP, 63(3): 139-149.

ARAÚJO OJB, MAIA RGN, JORGE-JOÃO XS \& COSTA JBS. 1988. A megaestruturação da folha Serra dos Carajás. In: Proceedings VII Cong. Lat. Amer. Geol., 324-333.

BARBOSA VCF, SILVA JBC \& MEDEIROS WE. 1999. Stability analysis and improvement of structural index estimation in Euler deconvolution. Geophysics, 64(1): 48-60.

BARBOSA VCF, SILVA JBC \& MEDEIROS WE. 2000. Making Euler deconvolution applicable to small ground magnetic surveys. J. Appl. Geophys., 43(1): 55-68.

BARBOSA VCF \& SILVA JBC. 2005. Deconvolução de Euler: passado, presente e futuro - um tutorial. Revista Brasileira de Geofísica, 23(3): 243-250.

BARROS CEM \& BARBEY P. 2000. Significance of garnet-bearing metamorphic rocks in the Archean supracrustal series of the Carajás Mining Province, Northern Brazil. Rev. Bras. Geoc., 30(3): 367-370. 
BARROS CEM, SARDINHA AS, BARBOSA JPO, KRIMSKI R \& MACAMBIRA MJB. 2001. Pb and U-Pb zircon ages of Archean syntectonic granites of the Carajás metallogenic Province, northern Brazil. In: Proceedings III South Amer. Symp. Isot. Geol., 94-97.

BARTON CE, BALDWIN RT, BARRACLOUGHD DR, BUSHATI S, CHIAPPINI M, COHEN Y, COLEMAN R, HULOT G, KOTZE P, GOLOVKOV VP, JACKSON A, LANGEL RA, LOWES FJ, MCKNIGHT DJ, MacMILLAN S, NEWITT LR, PEDDIE NW, QUINN JM \& SABAKA TJ. 1996. International Geomagnetic Reference Field, 1995 revision presented by IAGA Division V, Working Group 8. Phys. Earth Planet. Inter., 97: 23-26.

BRIGGS IC. 1974. Machine contouring using minimum curvature. Geophysics, 39: 39-48.

DALL'AGNOL R, LAFON JM \& MACAMBIRA MJB. 1994. Proterozoic Anorogenic Magmatism in the Central Amazonian Province, Amazonian Craton: Geochronological, Petrological and Geochemical Aspects. Mineral. Petrol., 50: 113-138.

DALL'AGNOL R, SOUZA ZS, ALTHOFF FJ, BARROS CEM, LEITE AAS \& JORGE-JOÃO XS. 1997. General aspects of the granitogenesis of the Carajás metallogenetic province. In: Proceedings Intern. Symp. Gran. and Assoc. Miner., Salvador, Excursion Guide, 135-161.

DOCEGEO. Rio Doce Geologia e Mineração S.A. 1988. Revisão litoestratigráfica da Província Mineral de Carajás - litoestratigrafia e principais depósitos minerais. In: Congresso Brasileiro de Geologia, 35., Belém: SBG, Anexo aos Anais, 11-54.

GALARZA TMA, MACAMBIRA MJB \& MOURA CAV. 2003. Geocronologia $\mathrm{Pb}-\mathrm{Pb}$ e $\mathrm{Sm}-\mathrm{Nd}$ das rochas máficas do depósito Igarapé Bahia, Província Mineral de Carajás (PA). In: VII Simp. Geol. Amaz. CD-ROM. GEOSOFT. 2006. OASIS Montaj ${ }^{\text {TM }}$, v. 6.4.1(6G) GEOSOFT, Inc., Toronto. HIRATA WK, RIGON JC, KADEKARU K, CORDEIRO AAC \& MEIRELES EA. 1982. Geologia Regional da Província Mineral de Carajás. In: Anais I Simp. Geol. Amaz., Belém - PA. 1: 100-110.

HOLDSWORTH R \& PINHEIRO R. 2000. The anatomy of shallow-crustal transpressional structures: insights from the Archean Carajás fault zone, Amazon, Brazil. J. Struct. Geol., 22: 1105-1123.

HSU S-K. 2002. Imaging magnetic sources using Euler's equation. Geophys. Prospect., 50: 15-25.

HSU S-K, SIBUET J-C \& SHYU C-T. 1996. High-resolution detection of geologic boundaries from potential-field anomalies: An enhanced analytic signal technique. Geophysics, 61(2): 373-386.

HUHN SRB, SANTOS ABS, AMARAL AF, LEDSHAM EJ, GOUVÊA JL, MARTINS LPB, MONTALVÃO RMG \& COSTA VG. 1988. 0 terreno "granite-greenstone" da Região de Rio Maria - Sul do Pará. In: Anais XXXV Congr. Bras. Geol., Belém - PA. 3: 1438-1452.

LEITE EP \& SOUZA FILHO CR. 2009a. Probabilistic neural networks applied to mineral potential mapping for platinum-group elements in the Serra Leste region, Carajás Mineral Province, Brazil. Comput. Geosci., 35(3): 675-687.

LEITE EP \& SOUZA FILHO CR. 2009b. Artificial Neural Networks Applied to Mineral Potential Mapping for Copper-Gold Mineralizations in the Carajás Mineral Province, Brazil. Geophys. Prospect., 57(6): 1049-1065.

LI J, MOROZOV IB \& CHUBAK G. 2005. Potential-field investigations of the Williston Basin basement. In: Summary of Investigations 2005, vol. 1, Saskatchewan Geological Survey, Misc. Rep. 4.1, CD-ROM, Paper A-5, $11 p$.

MACHADO N, LINDENMAYER DH, KROUGH TE \& LINDENMAYER ZG. 1991. U-Pb geochronology of Archean magmatism and basement reactivation in the Carajás area, Amazon Shield, Brazil. Precambrian Res., 49: $1-26$.

MONTEIRO LVS, XAVIER RP, HITZMAN MW, CARVALHO ER, JOHNSON CA, SOUZA FILHO CR \& TORRESI I. 2007. Spatial and temporal zoning of hydrothermal alteration and mineralization in the Sossego iron oxide copper gold deposit, Carajás Mineral Province, Brazil: paragenesis and stable isotope constraints. Miner. Deposita, 43: 129-159.

MURDIE ER, STYLES P, UPTON P, EARDLEY P \& CASSIDY NJ. 1999. Euler deconvolution methods used to determine the depth to archaeological features. In: Geoarchaeology; exploration, environments, resources. Geological Society, Special Publications, 165: 35-40.

MUSZALA SP, GRINDLAY NR \& BIRD RT. 1999. Three-dimensional Euler deconvolution and tectonic interpretation of marine magnetic anomaly data in the Puerto Rico trench. J. Geophys. Res., 104(B12): 2917529187.

NABIGHIAN MN. 1972. The analytic signal of two-dimensional magnetic bodies with polygonal cross-section: its properties and use for automated anomaly interpretation. Geophysics, 37: 507-517.

NABIGHIAN MN. 1974. Additional comments on the analytic signal of two-dimensional magnetic bodies with polygonal cross-section. Geophysics, 39: 85-92.

OLIVEIRA NV, ENDO I \& OLIVEIRA LGS. 2005. Geometria do Sinclinal Gandarela baseada na Deconvolução Euler 2D e 3D - Quadrilátero Ferrífero (MG). Revista Brasileira de Geofísica, 23(3): 221-232.

PHILLIPS JD. 1997. Potential Field Geophysical Software for the Pc, version 2.2: USGS Open-File Report 97-725, 34p. Disponível em: $<\mathrm{ftp}$ ///tpext.usgs.gov/pub/cr/co/denver/musette/pub/pf/>. Acesso em: 14 jul. 2008.

PHILLIPS JD. 2001. Processing and interpretation of aeromagnetic data for the Santa Cruz basin-Patagonia Mountains area, south-central Arizona - a preliminary report. USGS Open-File Report 02-98, 15 p.

PIMENTEL MM, LINDENMAYER ZG, LAUX JH, ARMSTRONG $R$ \& ARAÚJO JC. 2003. Geochronology and $\mathrm{Nd}$ isotope geochemistry of 
the Gameleira Cu-Au deposit, Serra dos Carajás, Brazil: 1.8-1.7 Ga hydrothermal alteration and mineralization. J. South Am. Earth Sci., 15: 803-813.

PINHEIRO RVL \& HOLDSWORTH RE. 1997. Reactivation of Archaean Strike-Slip Fault Systems, Amazon Region, Brazil. J. Geol. Soc. London, 154: 99-103.

REID AB, ALLSOP JM, GRANSER H, MILLETT AJ \& SOMERTON IW. 1990. Magnetic interpretation in three dimensions using Euler deconvolution. Geophysics, 55(1): 80-91.

RODRIGUES ES, LAFON JM \& SCHELLER T. 1992. Geocronologia PbPb da Província Mineral de Carajás: primeiros resultados. In: Bol. Res. Exp. XXXVII Cong. Bras. Geol., 2: 183-184.

ROEST WR, VERHOEF J \& PILKINGTON M. 1992. Magnetic interpretation using the 3-D analytic signal. Geophysics, 57(1): 116-125.

SMITH RS \& SALEM A. 2005. Imaging depth, structure, and susceptibility from magnetic data: The advance source-parameter imaging method. Geophysics, 70(4): L31-L38.

SOUZA FILHO CR, NUNES AR, LEITE EP, MONTEIRO LVS \& XAVIER RP. 2007. Spatial analysis of airborne geophysical data applied to geological mapping and mineral prospecting in the Serra Leste region, Carajás Mineral Province, Brazil. Surv. Geophys., 28: 377-405.

SUITA MTF \& NILSON AA. 1988. Geologia do complexo máfico-ultramáfico Luanga (Província Mineral de Carajás, Pará) e das unidades encaixantes. In: Anais XXXV Cong. Bras. Geol. Belém, 6: 2813-2823.
TALLARICO FHB, COIMBRA CR \& COSTA CHC. 2000. The Serra Leste sediment-hosted Au-(Pd-Pt) mineralization, Carajás Province. Rev. Bras. Geoc., 30(2): 226-229.

TALLARICO FHB, McNAUGHTON NJ, GROVES DI, FLETCHER IR, FIGUEIREDO BR, CARVALHO JB, REGO JL \& NUNES AR. 2004. Geological and SHRIMP II U-Pb constraints on the age and origin of the Breves CuAu-(W-Bi-Sn) deposit, Carajás, Brazil. Miner. Deposita, 39: 68-86.

THOMPSON DT. 1982. EULDPH: A new technique for making computerassisted depth estimates from magnetic data. Geophysics, 47(1): 31-37.

THURSTON JB \& SMITH RS. 1997. Automatic conversion of magnetic data to depth, dip, and susceptibility contrast using the SPI - method. Geophysics, 62(3): 807-813.

TRENDALL AF, BASEI MAS, DE LAETER JR \& NELSON DR. 1998. SHRIMP U-Pb constraints on the age of the Carajás Formation, Grão Pará Group, Amazon Craton. J. South Am. Earth Sci., 11: 265-277.

WIRTH KR, GIBBS AK \& OLSZEWSKI WJ. 1986. U-Pb ages of zircons from the Grão Pará Group and Serra dos Carajás granite, Pará, Brazil. Rev. Bras. Geoc., 16: 195-200.

YAGHOOBIAN A, BOUSTEAD GA \& DOBUSH TM. 1992. Object delineation using Euler's Homogeneity Equation. Location and Depth Determination of Buried Ferro-Metallic Bodies. Proceedings SAGEEP 92, 613-632.

\section{NOTAS SOBRE OS AUTORES}

Manuel Gomes Correia. Possui graduação em Engenharia Geológica pela Universidade de Aveiro (2006) e mestrado em Engenharia Geológica pela Universidade de Aveiro (2008). Atualmente é doutorando em Ciências e Engenharia de Petróleo na UNICAMP e trabalha com pesquisa em simulação e gerenciamento de reservatórios de petróleo.

Emilson Pereira Leite. Bacharel em Geofísica (USP, 1997); Mestre em Geofísica (USP, 2000); Doutor em Geofísica (USP, 2005) com estágio no Department of Earth and Space Science and Engineering, Universidade de York, Toronto/CAN. Atualmente é Professor Doutor do Departamento de Geologia e Recursos Naturais da UNICAMP. Suas principais áreas de interesse são: métodos potenciais em Geofísica, inversão de dados geofísicos, sensoriamento remoto e integração de dados geofísicos e geológicos para mapeamento do potencial mineral e exploração de hidrocarbonetos.

Carlos Roberto de Souza Filho. Engenheiro Geólogo (UFOP, 1988), Mestre em Metalogênese (UNICAMP, 1991), PhD (Open University, Inglaterra, 1995), JovemPesquisador (FAPESP-UNICAMP, 1995-1997), Professor-Doutor (UNICAMP, 1997-2002). Desde 2009, é Professor Titular do DGRN-IG-UNICAMP. Pesquisador Nível 1 A do CNPq e da NASA (programas ASTER e Mars-Earth Analogs), e Editor-Associado da Revista Computers \& Geosciences. Sua área de interesse é em Mapeamento Geológico e Exploração Mineral e Petrolífera com base em dados e métodos de Sensoriamento Remoto, Aerogeofísica e Sistemas de Informações Georreferenciadas. 